\title{
Erratum to: Role of hysteroscopy in the detection of endometrial pathologies in women presenting with postmenopausal bleeding and thickened endometrium
}

\author{
Amr K. Elfayomy • Fawzia A. Habib • \\ Mohamed A. Elkablawy
}

Published online: 12 December 2014

(c) Springer-Verlag Berlin Heidelberg 2014

Erratum to: Arch Gynecol Obstet (2012) 285:839-843

DOI 10.1007/s00404-011-2068-6

Unfortunately, the author Mohamed A. Elkablawy name was published with typos in the original publication. Additionally, one of his affiliations was completely omitted. The correct detail is given below.

Mohamed A. Elkablawy

Pathology Department, Faculty of Medicine, Menoufyia University, Menufia, Egypt

Department of Pathology, Faculty of Medicine, Taibah University, Al-Madinah Al-Munawarah, Saudi Arabia

The online version of the original article can be found under doi:10.1007/s00404-011-2068-6.

\footnotetext{
A. K. Elfayomy

Department of Obstetrics and Gynecology, Faculty of Medicine,

Zagazig University, Zagazig, Egypt

A. K. Elfayomy $(\bowtie) \cdot$ F. A. Habib

Department of Obstetrics and Gynecology, Faculty of Medicine,

Taibah University, Al-Madinah Al-Munawarah, Saudi Arabia

e-mail: amr.fyomy@yahoo.com
}

M. A. Elkablawy

Department of Pathology, Faculty of Medicine, Taibah

University, Al-Madinah Al-Munawarah, Saudi Arabia

M. A. Elkablawy

Pathology Department, Faculty of Medicine, Menoufyia

University, Menufia, Egypt 